\title{
How Many People Are Involuntarily Childless?
}

\author{
TURID NOACK
}

\author{
Research Fellow \\ Division for Social and Demographic Research \\ Statistics Norway \\ Oslo, Norway
}

\begin{abstract}
The number of permanently childless women has fluctuated considerably among the Norwegian women born in this century, from less than ten percent to twice that. Childlessness, especially involuntary childlessness, receives far more attention today than it did 15 to 20 years ago. Delayed childbearing and innovation developed in the field of modern reproduction technology have heightened interest in childlessness. Some people seem to believe that the incidence of reproduction problems has increased steadily and is well on its way to assuming epidemic proportions. Others make a point of childlessness by choice. Emphasis is attached to clarifying the terminology used to discuss different ways of distinguishing childlessness and types of childlessness. The data have been taken from two major interview surveys, the Fertility Survey 1977 (FS 77) and the Family and Occupation Survey 1988 (F\&O 88). Our findings do not indicate that infecundity became more common during the decade covering the latter half of the 1970 s and early half of the 1980 s. The total percentage of permanently childless women shows signs of increasing slightly from its level of just less than ten percent. This increase is probably due as much to "voluntary" as involuntary childlessness.
\end{abstract}

Keywords: childless women, infecundity, infertility, Norway

\section{Introduction}

Demographic fertility analyses mainly refer to the number of women who bear children, the length of the intervals between births and women's ages when they give birth. This paper, on the other hand, deals exclusively with how many people do not have children and who they are, focusing primarily on those who remain childless for life. Accordingly, this is about the women who have not given birth by the time they reach menopause.

The number of permanently childless women has fluctuated considerably among the Norwegian women born in this century. The largest percentages of childless women were in the cohorts born right after the turn of the century. It is estimated that more than one in five women born in 1910 never had children of her own (Noack and Texmon 1991). The lowest percentages of childless women were those in the cohorts born in the 1930 s and 1940 s, when slightly fewer than one in ten remained childless (Kravdal 1994). For the younger cohorts, i.e. women born after the mid-1950s, we do not yet know how many will never have children. The fertility pattern up until the age of 35 
may indicate that there may be a slight rise in the percentage who remain permanently childless.

Childlessness, especially involuntary childlessness, receives far more attention today than it did 15 to 20 years ago. The subject is now discussed openly, often sparking debates. Support groups have been formed for the childless, and childlessness is the focus of wide-ranging, extensive interdisciplinary research. Two parallel but different phenomena have heightened the interest taken in childlessness: One is the change in birth patterns due to delayed childbearing, the other is the wide range of innovations developed in the field of modern reproduction technology.

The percentage of women who had not become mothers by their 30th birthday increased notably for the cohorts born in the 1950 s, from 16.7 percent of women born in 1950 to 25.0 percent of the 1959 cohort (Kravdal 1991). Similar increases have been observed in a number of other countries at more or less the same time. There is, however, a considerable variation in patterns. In a country-specific overview of development, many European countries show higher age at first birth and have had a stronger delay than Norway (Beets 1995). In the Netherlands, for example, 38.7 percent of the women born in 1960 were childless at the age of 30 compared to 24.3 percent of Norwegian women. In the USA the percentage of childless women in their late twenties and early thirties nearly doubled in the 1970s (Baldwin and Nord 1984). Some researchers believed this trend indicated that we were facing a sharp rise in the percentage of women who would remain childless for life (Bloom and Pebley 1982; Finnäs 1984). As far as the USA was concerned, Bloom and Pebley estimated that the percentage of the permanently childless could be as high as 30 percent for the 1954 cohort.

The expectations of a rapid increase in the percentage of permanently childless women were based on the belief that a growing percentage of women would opt to remain childless, turning instead to higher education and careers. It was also expected that more women might suffer from serious and to some extent insurmountable reproductive problems because they were delaying childbearing for so long that their natural fecundity would be reduced significantly before they finally decided to have children.

At roughly the same time as the tendency to delay childbearing was noted, important breakthroughs were made in the field of reproduction technology. In vitro fertilization (IVF) termed as the test tube method, created quite a stir. The world's first testtube baby was born in 1978, but the method was still considered experimental (Population Reports 1983) when the first IVF baby was born in Norway five years later. In the past few years the method has seen much wider use and approximately 0.5 percent of all babies are now conceived in this way (Daltveidt 1995). From 1988 to 1993, the Medical Birth Registry of Norway recorded some 3,000 IVF pregnancies (Medical Birth Registry of Norway 1995).

In the field of reproduction technology, IVF, donor insemination and surrogate mothering have attracted considerable attention. However, it appears as though the general public is growing more interested in what can and should be done to help those who are involuntarily childless. The new treatment techniques raise a number of ethical questions, some of which are so serious that Norway has adopted a special law on artificial insemination. In the wake of these often resource-intensive methods of treatment, it was inevitable that there would be a health policy debate regarding the priority that should be assigned to treatment of the involuntarily childless in comparison with other health care needs. For 1991, for example, it is estimated that IVF treatment alone cost the public purse a total of some NOK 20 million (Hellum 1995). The increasing focus on the treatment of involuntary childlessness must also be viewed against the background of therapists' desire to reach as many potential patients as possible and to initiate treatment at an earlier age than what was the custom 20 to 30 years ago. 
It has been pointed out that the strong interest shown in the treatment of involuntary childlessness has led people to believe that the incidence of reproduction problems has increased steadily and is well on its way to assuming epidemic proportions (Mosher and Pratt 1990). In more popular depictions, there is also a tendency to view many of those who do not have children as potential patients and items of expenditure on public health budgets. One of the goals of this paper is to provide a more detailed picture of the scope of permanent childlessness.

\section{Terminology}

\section{a) Voluntary and i nvoluntary childlessness}

The terms "involuntary" and "voluntary" childlessness are often used in everyday speech. Involuntary childlessness is used to describe those who want to have children (or more children) but who, for various medical reasons, are unable to reproduce. On the other hand, the voluntarily childless are those who are childless because they do not want children. The use of these definitions implies the existence of two dimensions, the desire to have children and the ability to have them, which have been juxtaposed into four categories (Figure 1).

A vast majority of women want children and have the ability to translate this desire into practice (upper left category in Figure 1). The two dimensions also coincide in the lower right category, those who have neither the desire for nor the ability to have children. It is hard to determine the size of this group empirically since the inability to reproduce is usually only revealed following active attempts to have children. For most intents and purposes, this group can be viewed in conjunction with those who are voluntarily childless.

The involuntarily childless, as defined here, want children but are not able to have them due to reproduction problems. The term is often used to refer to both primary and secondary childlessness, i.e. to women who already have children but have not managed to have more. Estimates regarding the size of this group and information about

Figure 1.

\section{Desire to have children}

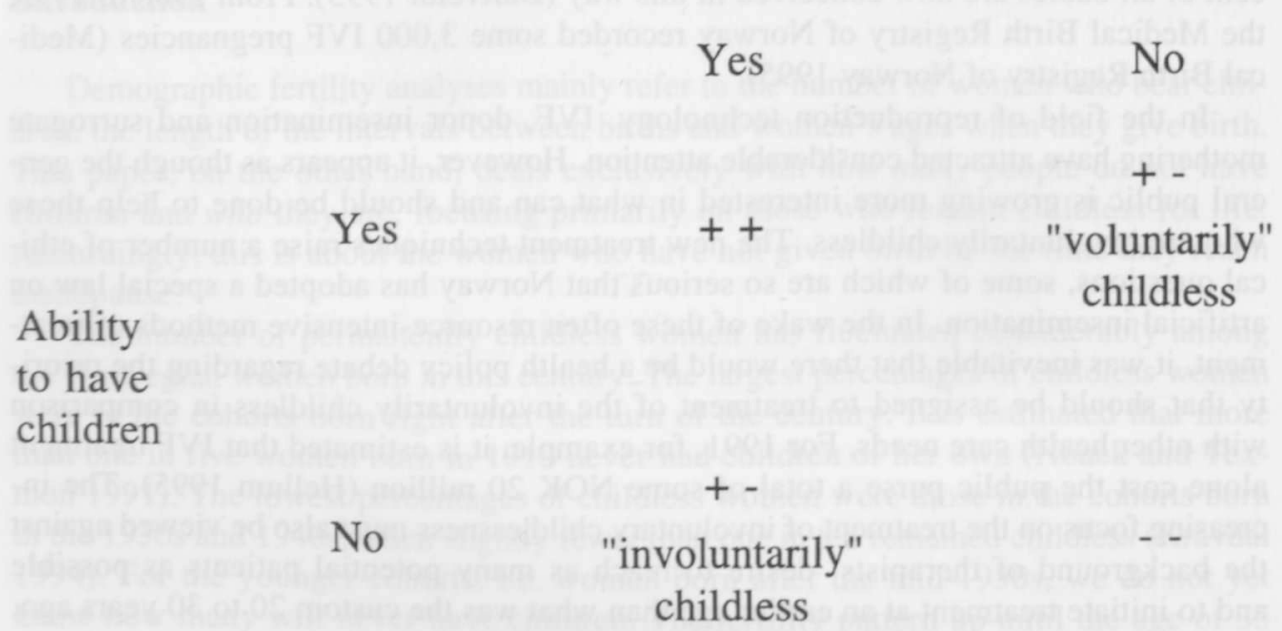


development trends are essential for predicting the scope of the medical treatment needed.

The term "voluntarily" childless is often determined residually, i.e. it is used to refer to all childlessness where there is no acknowledged failure to reproduce. Used in this manner, "voluntary" is not contingent on a subjective experience of free choice. As defined in Figure 1, those who are "voluntarily" childless also include those who have not had children because the ambient conditions have not been appropriate for motherhood. Some may have refrained from having children because they had no acceptable partner at the appropriate time. For others, their health or different socioeconomic conditions may have tipped the scales away from having children. The "voluntarily" childless group will also include those who give priority to activities other than motherhood, as well as those who have actively rejected motherhood based on the basis of ideological beliefs. As a group, the "voluntarily" childless are far more heterogeneous than the images often conjured up stereotyped labels such as "childfree" and "dinks" (double income, no kids), etc.

\section{b) Infecundity and infertility}

The terminology associated with the inability to become pregnant or to carry a baby to term is ambiguous. Demographers prefer to use the term fecundity to refer to the physiological ability to bear live babies and the antonym infecundity for the inability to conceive (Grebenik and Hill 1974). Medical literature uses infertility as a synonym for infecundity, and both demographers and physicians use the term sterile as a synonym for infecundity as well as infertility. Infecundity and infertility are also used to distinguish between the inability to conceive (infecundity) and the inability to conceive or to bring a pregnancy to term (infertility) (Population Reports 1983). In other words, the group classified as infertile will be somewhat larger than the group classified as infecund.

I have elected to use the term infecundity even though it is becoming increasingly more common in demographic analyses to refer to infertility rather than infecundity. Otherwise, it is worth noting that the term infertility seems to have become rather commonly accepted outside of professional circles.

As used here, infecundity generally fits the same definition as infertility: "Biologically, infertility is a physiological and/or anatomical malfunction or disorder in a system of interactions in and between two individuals of the opposite sex in order to produce offspring" (Sundby 1994). In these terms, it is strictly speaking only the couple's, not the individual's, ability to reproduce that can be measured.

Epidemiological surveys of diseases often use measures for prevalence as well as incidence to indicate the spread of a disease. Getting prevalence and incidence data on infecundity is more difficult than for most diseases and injuries. While many conditions can be diagnosed by specific tests and symptoms, a confirmation of infecundity may call for a number of very different tests and the diagnostic process will often involve both partners. Nor is infecundity restricted to a particular point in time; it more commonly refers to a specific period of observation. For clinical purposes, it is usual to define infecundity as the failure to become pregnant after one or possibly two years of having regular sexual intercourse without using contraceptives.

\section{c) Primary and secondary infecundity}

A distinction is often made between primary infecundity, i.e. those who have never had children, and secondary infecundity, i.e. those affected by infecundity after one 
or more births. Obviously, a change of partner will be an important reason for changing fecundity status. As regards women, a range of different studies has been conducted to determine how the risk of infecundity changes throughout a woman's childbearing years. The increase in mothers' ages at the time of first birth has drawn attention to the question of the age at which age-related infecundity can be described as significant. One study that attracted considerable attention concluded that the risk of infecundity rises sharply already from the age of 30 (Federation CECOS, Schwartz and Mayaux 1982). Their results met some strong opposition, especially from demographic quarters (Bongaarts 1982, Menken 1985). Even though the demographic data are also subject to some uncertainty and sources of error, there are strong indications that there is no notable rise in infecundity until after the age of 35 .

\section{Objectives}

This paper is the first stage of a more comprehensive analysis of childlessness. The primary objective of this first stage is two-fold: First, emphasis has been attached to clarifying the terminology used to discuss different ways of distinguishing childlessness and types of childlessness, as well as to study the target problems associated with this type of data. Second, the paper reviews how widespread the different types of childlessness are, raising the question of whether the scope of permanent childlessness has changed in recent decades.

The next step in the analysis will be to examine how trends in voluntary and involuntary childlessness coincide with certain demographic and socioeconomic variables and with certain attitude-related variables. At this stage of the analysis, those who are infecund and voluntarily childless will have been monitored for two observation periods of 16 and 5 years, respectively, to test the stability of the conditions at the individual level.

\section{Data}

\section{A) Sampling and non-response}

The data have been taken from two major interview surveys, the Fertility Survey 1977 (FS 77) and the Family and Occupation Survey 1988 (F\&O 88). Both surveys were conducted by Statistics Norway. A total of 4,137 and 4,019 women, respectively, were interviewed, usually at home. The sample in FS 77 is statistically representative for Norwegian women born from 1933-1959, while the F\&O survey is representative of the birth cohorts born in 1945, 1950, 1955, 1960, 1965, and 1968. Non-response amounted to 18 and 19 percent respectively in the two surveys.

Considering that both surveys were strongly oriented towards children and families, it was expected that non-response would be somewhat higher among women who did not have children, especially women belonging to cohorts in which the majority of members had already started families. With a few exceptions, the recorded data shows whether or not the women in the gross samples had experienced any live births. Nonresponse was highest among childless women in both surveys, 25 percent in FS 77 and 21 percent in F\&O 88 (Table 1). Not unexpectedly, non-response was especially high among women in their $30 \mathrm{~s}$ and 40 s. However, they comprise a rather small percentage of all the women in these age groups. 
$\mathrm{T}$ a b l e 1. Gross sample and the percentage of non-response among the various age groups of women with and without children. The Fertility Survey 1977 (FS77) and the Family and Occupational Survey 1988 (F\&O88).

\begin{tabular}{ccccc} 
Age (year of birth) & \multicolumn{2}{c}{$\begin{array}{c}\text { With children } \\
\text { Number of } \\
\text { women }\end{array}$} & Non-response & \multicolumn{2}{c}{$\begin{array}{c}\text { Without children } \\
\text { Number of } \\
\text { women } \\
\text { in gross sample }\end{array}$} & & $\begin{array}{c}\text { Non-respo } \\
\text { in gross sample }\end{array}$ \\
FS77 & 33 & 12.1 & 352 & 17.3 \\
$18-19(1958-59)$ & 378 & 15.1 & 689 & 23.8 \\
$20-24(1953-57)$ & 807 & 11.5 & 288 & 24.7 \\
$25-29(1948-52)$ & 878 & 12.6 & 148 & 33.1 \\
$30-34(1943-47)$ & 694 & 14.6 & 73 & 35.6 \\
$35-39(1938-42)$ & 620 & 20.3 & 70 & 42.9 \\
$40-44(1933-37)$ & & & & \\
F\&O88 & 109 & 19.3 & 766 & 17.4 \\
$20(1968)$ & 272 & 17.6 & 596 & 20.8 \\
$23(1965)$ & 557 & 12.7 & 309 & 18.8 \\
$28(1960)$ & 679 & 14.3 & 155 & 29.7 \\
$33(1955)$ & 705 & 19.4 & 82 & 28.0 \\
$38(1950)$ & 637 & 19.8 & 66 & 45.5 \\
$43(1945)$ & & & &
\end{tabular}

\section{B) Variables and definitions}

The classification of women with and without children is based on women's own reports of their pregnancy histories. They include all pregnancies, registered by outcome (spontaneous abortion/induced abortion/extra-uterine pregnancies/still births/live births) and each individual incident is registered by month and year.

- Women with children: All those who have experienced at least one live birth (regardless of whether their children were living at the time of the interview)

- Women without children: All those who had not experienced a live birth.

Fecundity status is based on the respondent's own assessment of her situation. FS 77 posed a simple question: "Do you think it would be possible for you to have a child now or later if you want to?" A total of 217 (5.2 percent of all those interviewed) were classified as infecund on the basis of this question. Sterilization is classified as a separate category, so it does not affect the figures for infecundity. F\&O 88 distinguished between the ability to get pregnant and the chances of bearing a pregnancy to term. The first question was as follows: "Do you believe it is physically possible for you to get pregnant now or later (with your husband/partner)? Do not consider whether or not you would be able to carry the child to term. All those who responded "yes" or "I don't know" to that question were asked to answer the following additional question: "Do you think it is physically possible for you to carry a child to term, provided you wanted to do so?" This resulted in 177 infecund women (4.4 percent of the sample), of which slightly less than one-third believed they could get pregnant but would not be able to carry the pregnancy to term. In principle, the one question posed in FS 77 was supposed to cover both the questions posed in F\&O 88. We have interpreted them as equal. The percentages who were uncertain about their own fecundity status were approximately equal in both investigations, i.e. 4.8 percent of those in FS 77 and 4.0 percent of those in F\&O 88 responded "I don't know" to the question regarding fecundity.

The question on fecundity was not posed to women who had never had intercourse ( 4.7 and 3.8 percent of the samples in FS 77 and F\&O 88, respectively) or to those 
who were pregnant at the time of the interview (4.6 percent in FS 77 and 4.7 percent in $\mathrm{F} \& \mathrm{O} 88$ ).

It would not be feasible to use clinical studies to survey the scope of infecundity in a normal population. The alternative is to use respondents' own reports. One way to do this is to determine how many of them did not have children, despite the fact that they engaged in regular sexual activity without using contraceptives during a given period of time. The requirement for being classified as infecund has usually been that the period last a minimum of one to two years. A different procedure, which does not involve as many questions, is to ask a direct question about the respondent's own assessment of her fecundity status. The figures presented here are based exclusively on such subjective evaluations.

All those classified as infecund were asked why they could not have children. Seven of ten seemed to be fairly certain about why they were infecund. They had either had their suspicions confirmed by a physician or considered themselves unable to have children due to illness on the part of themselves or their partner. The percentage who considered themselves infecund solely because they had not conceived was very small. There were no notable differences in the reasons given in the two surveys.

- Fecund women: All those of the opinion that they can conceive and carry a pregnancy to term

- Infecund women: All those of the opinion that they cannot conceive or carry a pregnancy to term

\section{Results}

\section{A) Permanently childless women}

Neither survey included women old enough to determine with complete certainty the percentage that would never have children. However, first births after the age of 40 are so rare that the reduction in the percentage of childless women throughout the remainder of their childbearing years must be expected to be extremely modest. For the cohorts born in the late-1930s, for example, the percentage of childless women was reduced by less than one-half percentage point during this period of their lives (Brunborg and Kravdal 1986, Kravdal 1991).

Figures $2 \mathrm{a}$ and $2 \mathrm{~b}$ show the percentage of childless women at different ages for the cohorts included in FS 77 and F\&O 88. At age 35, the percentage of childless women varies from 8.9 percent to 11.2 percent, averaging 9.6 percent. At age 40 , the childlessness figures are 6.6 percent and 8.0 percent. The percentage of childlessness in the two interview surveys was as expected, slightly lower than the share of childless people noted in registry surveys (Brunborg and Kravdal, 1986, Kravdal 1991). The difference varies between 0.2 and 2.7 percentage points, with an average of well under 2 percentage points.

Once we correct for sources of error - selective non-response among women without children and the fact that a few more will have children before the age of 50 , the percentage of childless women of 35 years of age seems to present a fairly good picture of those who will remain permanently childless. The highest percentage of permanently childless women is the 1950 cohort, with 11 percent, while the 1945 cohort has 9 percent.

As regards the cohorts born since the mid-1950s, we see a clear tendency to delay childbearing (Figure $2 b$ ). As mentioned earlier, this trend has also been registered in a number of other countries. However, it is still too early to tell whether these cohorts 
Figu re 2 a. Childless women of different ages. Women born from 1933 to 1953. Cumulative percentages.

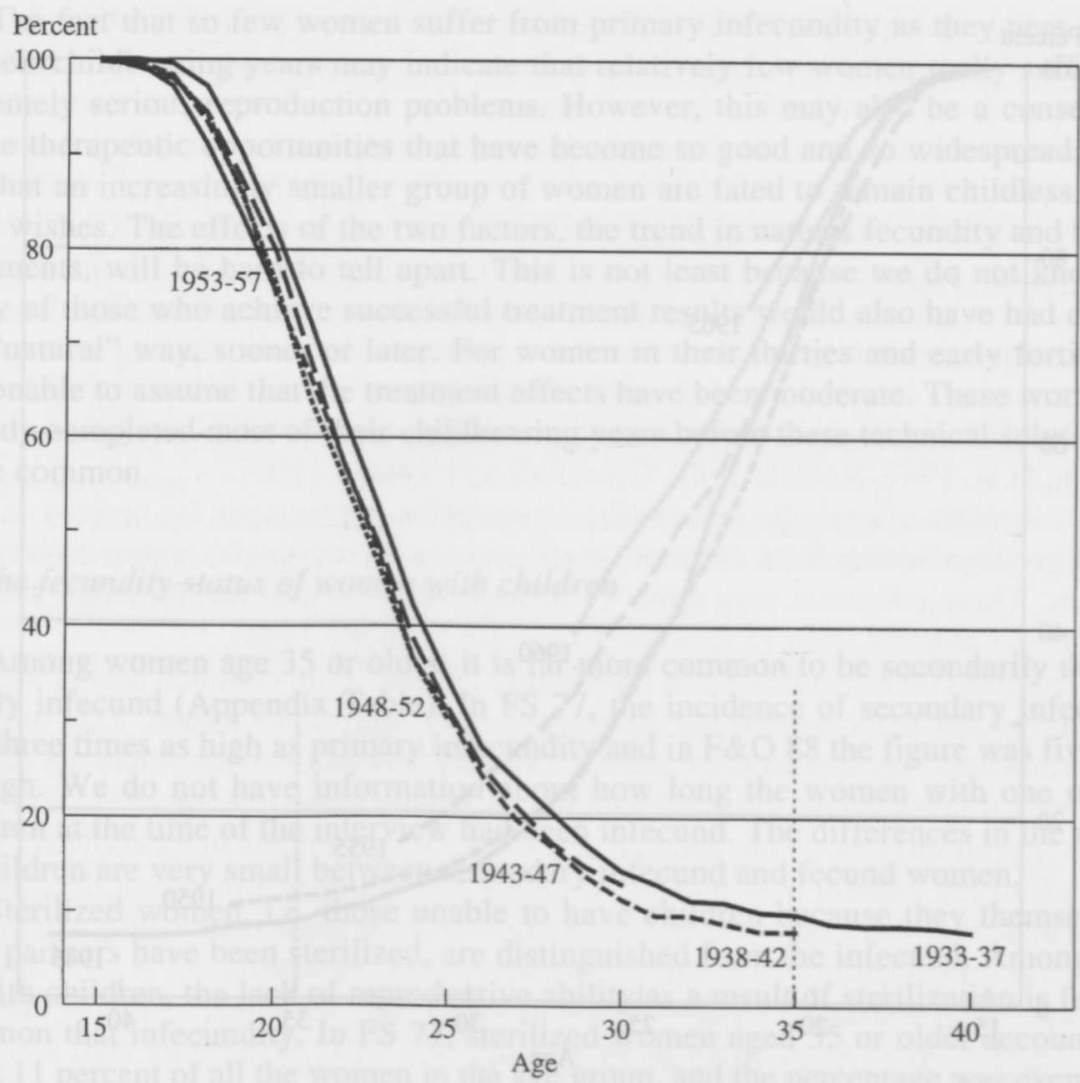

will end up with a higher proportion of "delayers" only or if permanent childlessness is on the rise.

In both interview surveys, all fecund women were asked how many children they expected to have. It has generally been found that women overestimate their future fertility behavior in fertility surveys, so at best, the surveys give rather uncertain indications about trends in the average number of children. However, it does not seem unreasonable to assume that an intentional switch in the direction of "voluntary" childlessness could be disclosed by this type of measure.

Of all those under the age of 30 who did not have children, there was almost no one (1-3 percent) in the two surveys who expected to remain childless. In other words, there are no signs that more younger women rejected motherhood in 1988 than in 1977. Of the few who remained childless during their early 30 s, there were fewer who expected to remain childless in F\&O 88 than in FS 77, 17 and 31 percent, respectively. This must be viewed in conjunction with the different selections of women who were already mothers. In 1977 the childless, fecund women in this age group accounted for 5 percent of the cohorts, while the comparable figure from the 1988 survey was 10 percent.

\section{B) Fecundity status for women without children}

If we compare the two investigations, the percentage of childless women suffering from such serious reproduction problems that they consider themselves infecund 
F i g u r e 2 b. Childless women at different ages. Women born in 1945, 1950, 1955, 1960 and 1965. Cumulative percentages.

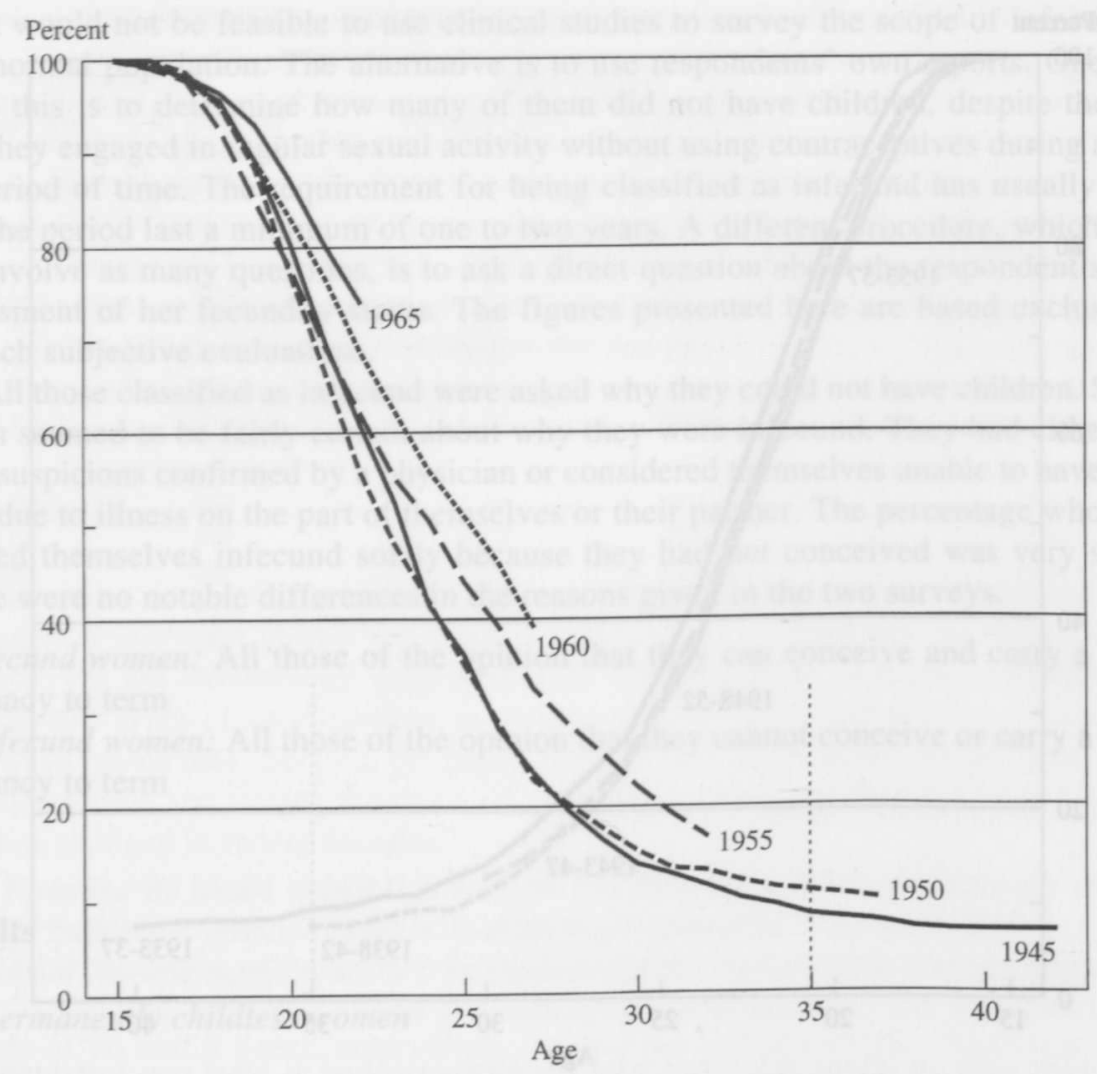

has not increased. Primary infecundity comprised 1.8 and 1.1 percent, respectively, of the women interviewed in FS 77 and F\&O 88.

Naturally, it is only to be expected that there will be a modest level of primary infecundity among women who are still so young that many have never tested their ability to have children. However, the percentage of primary infecundity is also small among the oldest women (Appendix Table). For women who were at least 35 years old at the time of the interview, the percentage of primary infecundity varied from 1.4 to 4.3 percent. These infecund women account for only about one-third of the entire group of the potentially permanently childless among these cohorts (born 1933-50). Although there is some variation among the cohorts, it generally appears that the "voluntarily" childless account for by far the largest proportion of those who never have children. This conclusion is also supported by other investigations.

The high percentage of non-response among older childless women leaves some doubt about estimates of the incidence of primary infecundity. It is also possible that infecund women are less interested in being interviewed than fecund childless women. If one presumes there is a larger share of infecundity in the gross sample than in the net sample and, for example, increases the percentage of infecundity up to $2 / 3$ of all childless women, the percentage of primary infecundity reaches a level of more than 6 percent for women of age 35 and older in the two investigations. Even based on these assumptions, the failure to reproduce, at least the permanent failure to reproduce, would not be very widespread. It must also be mentioned that the results and estimates presented here depend on the time of the interview. We do not know what 
proportion of these women may have been fecund for shorter or longer periods of time when they were younger.

The fact that so few women suffer from primary infecundity as they near the end of their childbearing years may indicate that relatively few women really suffer from extremely serious reproduction problems. However, this may also be a consequence of the therapeutic opportunities that have become so good and so widespread, entailing that an increasingly smaller group of women are fated to remain childless against their wishes. The effects of the two factors, the trend in natural fecundity and the new treatments, will be hard to tell apart. This is not least because we do not know how many of those who achieve successful treatment results would also have had children the "natural" way, sooner or later. For women in their thirties and early forties, it is reasonable to assume that the treatment effects have been moderate. These women had already completed most of their childbearing years before these technical solutions became common.

\section{C) The fecundity status of women with children}

Among women age 35 or older, it is far more common to be secondarily than primarily infecund (Appendix Table). In FS 77, the incidence of secondary infecundity was three times as high as primary infecundity and in F\&O 88 the figure was five times as high. We do not have information about how long the women with one or more children at the time of the interview had been infecund. The differences in the number of children are very small between secondary infecund and fecund women.

Sterilized women, i.e. those unable to have children because they themselves or their partners have been sterilized, are distinguished from the infecund. Among women with children, the lack of reproductive ability as a result of sterilization is far more common that infecundity. In FS 77, sterilized women aged 35 or older accounted for some 11 percent of all the women in the age group, and the percentage was even higher compared only with those women who have children. As far as sterilization is concerned, the percentage was significantly higher in 1988 than in 1977. In 1988 more than every fourth 43-year-old women and ever third 38-year-old woman was either sterilized herself or had a partner who was, and among the oldest group, sterilization was the most common form of contraception. Consequently, the contraception pattern among somewhat older women has changed significantly. The change is even greater because quite a proportion of the women in these age groups previously used unsafe contraception methods or no contraception at all (Noack and Østby 1991). The increase in the proportion of sterilizations may have had an indirect effect on the number of infecund women of various ages, since the risk group (those who might otherwise have become infecund with age) is smaller.

\section{Summary and discussion}

The health policy debate has to some extent been based on anecdotal estimates regarding the incidence of involuntary childlessness (Sundby 1994), and even the estimates that have originated from investigations are subject to considerable uncertainty. Estimates of infecundity have varied considerably. The large variations have a number of explanations, one of the most important of which appears to be differences in the use of terminology (such as the lack of any distinction between the temporary failure to reproduce and permanent problems), difficulties associated with measuring the phenomenon (such as the lack of good diagnostic tools), and variations in delimit- 
ing the risk group (which can be highly selective compared with a normal population, particularly in clinical studies).

The main emphasis of this paper is on permanent primary infecundity among women in the 35-44 age group, determined according to the respondents' "own diagnoses" and compared with total birth cohorts. Consequently, we are looking at those who remain childless for life, but not those who have only experienced episodic involuntary childlessness.

Surveyed in this way, primary infecundity is relatively rare, affecting $2-4$ percent of all women. Adjusted for selective non-response among the childless, particularly older childless women, the proportion of women with primary infecundity may be a few percentage points higher. The estimates of primary infecundity among women also include situations in which the failure to reproduce may be due to the woman's partner. Our estimates show relatively strong correlation with the results of other studies (Johnson, et al. 1987, Rantala 1988, Greenhall and Vessey 1990).

The estimates of periodic infecundity (cumulative percentages for periods of failure to reproduce lasting for a duration of at least one to two years) appear to be more uncertain. These estimates vary from 15 to more than 50 percent, although most of them seem to indicate from 15 to some 20 percent (Sundby 1994).

Our findings do not indicate that infecundity became more common during the decade covering the latter half of the 1970 s and early half of the 1980 s. This has also been corroborated by several other studies (Sundby 1994). However, there are figures from the USA that indicate a certain increase. A greater variety of improved treatment methods and an increase in the demand and supply of treatments in recent years make it difficult to tell exactly how natural fecundity has developed in recent decades. At present, however, there seems to be no sign that clinical finds such as, for example, a reduction in semen quality have had any notable effect on fertility.

Delayed childbearing is a phenomenon noted as from the cohorts born in the mid$1950 \mathrm{~s}$. There is more uncertainty as to whether this will, in the long run, lead to a larger share of permanently childless women. Thus far, among women at the end of their childbearing years, it has been more common to be fecund, i.e. "voluntarily" childless than infecund. The total percentage of permanently childless women shows signs of increasing slightly from its level of just less than 10 percent. This increase is probably due as much to "voluntary" as involuntary childlessness. It is more difficult to say whether this can be explained by a deliberate ideological choice of a childless lifestyle, i.e. a preference for material goods rather than children, etc. It may be equally reasonable to interpret such a development trend as the sum total of random, unfortunate circumstances that occur once the woman in question has intentionally delayed childbearing during her younger years.

\section{References}

Baldwin, W. H. and W.C. Nord. 1984. Delayed childbearing in the U.S.: facts and fictions. Population Bulletin 39(4).

Beets, G. 1995. Does the increasing age at first birth lead to increase in involuntary childlessness? Paper presented at the European Population Conference, Milan, 4-8 September 1995.

Bongaarts, J. 1982. Infertility After Age 30: A False Alarm. Family Planning Perspectives 14(2):758.

Bloom, D.E. and A.R. Pebley.1982. Childless Americans. American Demographics 1:18-21.

Brunborg, H. and $\varnothing$. Kravdal. 1986. Barnetall blant Norske kvinner: en paritetsanalyse pa grunnlag av registerdata (Fertility by birth order in Norway: a register-based analysis). Rapporter 86/27. Oslo-Kongsvinger: Statistics Norway.

Daltveidt, A.K. 1995. Personal report. 
Federation CECOS, Schwartz, D. and M.J. Mayaux.1982. Female Fecundity as a Function of Age. The New England Journal of Medicine 307:404.

Finnäs, F. 1984. Some aspects of the fertility development in Sweden 1960-1977. In: The Sixth Scandinavian Demographic Symposium, 16-19 June 1982 in Kungälv, Sweden: Studies in Fertility, pp. 147-159. Scandinavian Population Studies 6:2. Stockholm: The Scandinavian Demographic Society

Grebenik, E. and A. Hill. 1974. International demographic terminology: fertility, family planning and nuptiality, Paper no. 4, International Union for the Scientific Study of Population, Liège.

Greenhall, E. and M. Vessey. 1990. The prevalence of subfertility: a review of the current confusion and a report of two new studies. Fertility Sterility 54:978-982.

Hellum, A. 1995 Original title in Norwegian? (Childlessness as a global challenge to women's rights: gender and society in flux). Conference report. The Research Council of Norway.

Johnson, G. et al. 1987. Infertile or childless by choice? A multipractice survey of women aged 3550. British Journal of Clinical Research 294:804-806.

Kravdal, Ø. 1991. Sociodemographic Studies of Fertility and Divorce in Norway with Emphasis on the Importance of Economic Factors. Social and Economic Studies No. 90, Oslo-Kongsvinger: Statistics Norway.

Menken, J. 1985. Age and fertility: how late can you wait? Demography 22:469-483.

Medical birth registry of Norway. 1995. Annual Report for 1993. Medical birth registry of Norway/ University of Bergen/National Institute of Public Health.

Mosher, W.D. and W.F. Pratt. 1990. Fecundity and Infertility in the United States, 1965-88. Advance Data from vital and health statistics; No. 192. Hyattsville, MD: National Center for Health Statistics.

Noack, T. and I. Texmon. 1991. Dagens og morgendagens gamle kvinner - en demografisk beskrivelse (The old women of today and tomorrow - a demographic description.). In: Gamle kvinner i Norden - deres liv i tekst og tall, edited by Anne Helset, pp. 47-74. Report No. 6. Oslo: Norwegian Institute of Gerontology.

Noack, T. and L. Østby. 1991. (Original title in Norwegian should be placed here) More effective use of contraception. Samfunnsspeilet 3:20-24.

Population Reports. 1983. Infertility and Sexually Transmitted Disease: A Public Health Challenge. Series L, no. 4. Baltimore, MD: The Johns Hopkins University.

Rantala, M.L. 1988. Epidemiological and clinical studies on the etiology of infertility. Helsinki University of Helsinki. Doctoral Dissertation.

Sundby, J. 1994. Infertility - causes, care and consequences. Oslo: The Department of Epidemiology, National Institute of Public Health and Section for Medical Anthropology, Department Group for Community Medicine, University of Oslo. Medical dissertation. 


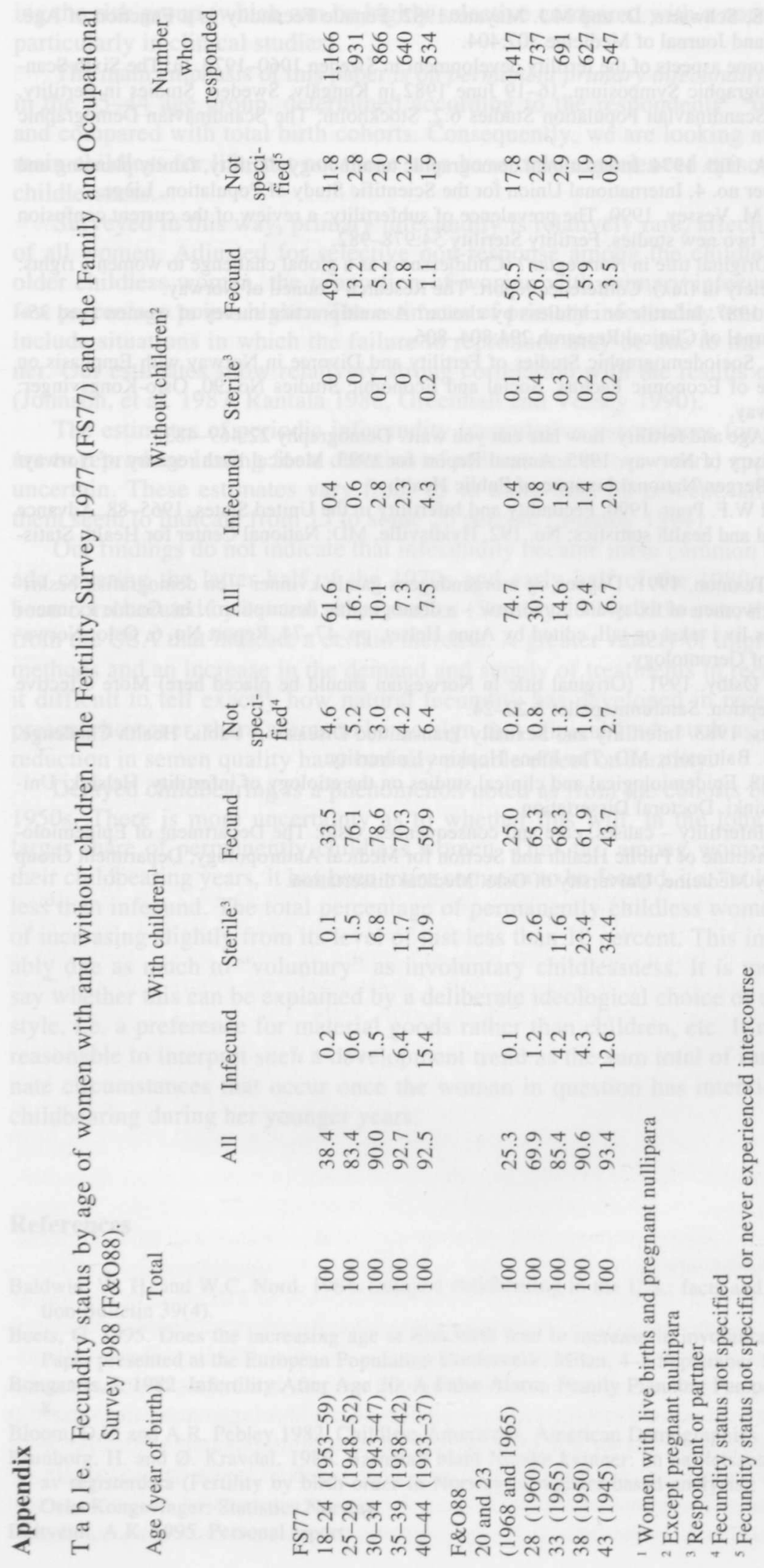

